\title{
'Small stories of closing loops': social circularity and the everyday circular economy
}

\section{Kersty Hobson ${ }^{1}$}

Received: 7 August 2018 / Accepted: 18 June 2019 /Published online: 6 July 2019

(C) The Author(s) 2019

\begin{abstract}
There is now no doubt that current global production-consumption-disposal systems are threatening the fundamental conditions of existence on this planet. In response, the pressing need for total system transformation has gained civic and political traction, feeding into longstanding debates and interventions that are aimed at recalibrating prevailing economic and social practices. One such debate and intervention is that of the circular economy (CE). Here, advocates argue that current linear resource and energy use systems must be reconfigured into loops of re-use, repair, refurbishment, and recycling, displacing primary production and lessening greenhouse gas emissions in the process. This agenda has potentially profound implications for aspects of daily social practices. Yet, to date, little attention has been paid (politically and in research) to how the CE does and will interact with everyday habits, norms, and meanings. In response, this paper explores some of the conceptual assumptions underlying the $\mathrm{CE}$ 'consumer'. It argues that mainstream $\mathrm{CE}$ debates are underscored by an impoverished view of our relationships with complex material cultures, which in turn is creating barriers to transformation. Drawing on empirical research into responses to the CE in the UK and the Netherlands, this paper contrasts the challenges of inciting consumers to take up new, resource-efficient business models in contexts of hyper-consumerism, with a more hopeful 'small story' of overt, small-scale circular spaces, that nevertheless embed the CE and its underlying impetuses more clearly into the everyday.
\end{abstract}

\section{Introduction}

Researchers and commentators have argued for decades that the modus operandi of piecemeal responses to the multiple anthropogenic threats that our planet is facing is woefully inadequate. The fact that there is now a 'substantial risk of destabilising the Holocene state of the Earth

This article is part of the Special Issue on "Everyday Climate Cultures: Understanding the cultural politics of climate change" edited by Goodman, Doyle and Farrell

Kersty Hobson

hobsonk@cardiff.ac.uk 
system in which modern societies have evolved' (Steffen et al. 2015, p. 736) means that a bit of recycling here and some emissions trading there is no longer a sufficient response. Indeed, the unholy alliance of ecological depletion, environmental degradation, and widespread climate change impacts has led some to argue that we are 'very rapidly cross irreversible thresholds to completely new and less desirous environmental states' (e.g. McBain et al. 2017, p. 18).

Such grim prognoses have informed calls for radical shifts in intertwined global systems: messages that, in the past, were often side-stepped and downplayed in mainstream environmental debates (e.g. Fuchs and Lorek 2005). For example, the recent Intergovernmental Panel on Climate Change 'special report' on $1.5^{\circ} \mathrm{C}$ warming garnered significant media and political attention (IPCC 2018), arguably altering the role this institution has previously held, from a supposed science-only, non-political entity (see Beck and Mahony 2018) to one advocating immediate and large-scale action. The United Nations now uses the language of 'transformation' (see United Nations 2015): while a recent European Environment Agency (EEA 2018) report 'Perspectives on transition to sustainability' states that:

Europe must go beyond incremental improvements in environmental performance.

Instead, it must find ways to achieve fundamental transitions or transformations in core systems, entailing 'profound changes in dominant institutions, practices, technologies, policies, lifestyles and thinking (EEA 2018, p. 6)

Of course, the obvious follow-up question to such a statement is, how to go about this? How to alter the fundamental aims, logics, processes, and structures that have underpinned the past few hundred years (at least) of rapid socio-economic change and parallel environmental despoilment and to do so in a timely, effective, and equitable manner?

Such questions are at the forefront of many researchers', activists', and practitioners' minds, as they theorise about, and experiment with, myriad ways to create transformative outcomes across a range of scales, spaces, and systems. There are, for example, clear cases made for rethinking and recalibrating current economic norms and systems (Jackson 2009; Raworth 2018), which include highlighting the many problems that arise from using the gross domestic product as the marker of national 'well-being' (Pool 2018). There are grassroots, locally based ways of living, sharing, and creating (e.g. transition initiatives, community energy groups, repair cafe, and community currencies) and global collectives of sub-national actors (e.g. local government, researchers, and service providers) such as ICLEI's 'Urban Transitions Alliance' (Urban Transitions Alliance 2019). The differential scale and purpose of these examples underscore both the richness of responses and the inevitable challenges they all must face. For one, the sense of linearity and boundedness that phrases like 'core systems' (ibid.) convey belie the observed 'organised complexity' of inter-related (financial, ecological, etc.) systems: a complexity that some argue requires the generation of 'novel insights, from new business models to complementary currencies to open-source design' (Raworth 2018, p. 158).

This paper picks up one thread of Raworth's point, exploring how some apparent 'novel insights' from 'new business models' land in the spaces and practices of the everyday. It is based on the premise that, if attempts at system transformation are to have socially and environmentally meaningful impacts (however defined), there is a need to understand more about how they meet and interact with extant quotidian processes and spaces (Mylan 2015). Such work undoubtedly already exists across a range of disciplines (e.g. see Smith et al. 2014; Seyfang and Longhurst 2016). Yet, arguably more needs to be understood, conceptually and empirically, particularly as general calls for transformation take on the shape of specific models 
of, and programmes for, system interventions, some of which are solidifying in the public sphere as prevailing models for change.

\subsection{Circularity as a model for socio-technical change}

The particular 'change' model this paper focuses on is that of the circular economy (CE). At its most basic, the $\mathrm{CE}$ is a framework aimed at shifting current linear production-consumptiondisposal systems into loops of redesign, repair, re-use, remanufacture, and recycling (Ellen MacArthur Foundation 2012, 2015). Built upon decade-old debates from diverse fields (e.g. sustainable design and industrial ecology) and now a key pillar of the European Union's regional growth strategy (see European Commission 2015), the CE advocates calls for the ramping up of current interventions (e.g. improved recycling rates and methods). In addition, they advocate the introduction of new forms of material practices, some of which are reconfigurations of older modes of consuming, e.g. the so called sharing economy (SE; see Ellen MacArthur Foundation 2017).

Such shifts in prevailing systems heavily implicate us all, as consumers and users of goods and services. For example, within the CE, changes to business models are often framed under the concept of 'sustainable product service systems' (SPSS; see Robin 2000). This idea focuses on the reconfiguration of how our material needs are met, to 'enable the less material-intensive provision of services to customers by selling solutions rather than products' (Liedtke et al. 2015, p. 106). One example of this is renting modular and recycled floor coverings from companies such as Interface (see Interface 2019) rather than buying and owning a carpet that is used and then thrown out quite probably into landfill.

Although renting floor coverings may seem a minor change to current practices, such SPSSs do impact how we all collectively perceive, use, and repair goods and services (Bridgens et al. 2019; Hobson et al. 2018). Building upon recent research (e.g. Hobson and Lynch 2016), this paper thus argues that, to date, CE advocates and interventions have paid too little attention to such potential and actual impacts. In our provisioning practices, our role in the CE is often framed as one of general passivity, accepting or rejecting new business models, as well as being amenable to shifts in collective identities from being 'consumers' of goods to being 'users' of goods and services (Ellen MacArthur Foundation 2015).

Research to date however suggests that the uptake of trialled SPSSs is less than promising (see Tukker 2004), and the SE is replete with pitfalls and unwarranted positive assertions about social and environmental impacts (e.g. see Hobson and Lynch 2016). This may be because new SPSSs and forms of SE simply need further development and tweaking before the public buy into them, as some of the SPSS literature suggests. However, this paper instead argues that part of the CE problem is that it is operating under an impoverished theory of both human action and the contexts that are being transformed, given the complex entanglements of materials, capabilities, and meanings (e.g. see Shove and Walker 2007) that constitute our everyday lives. This is not a minor consideration. There have already been clear warnings that the $\mathrm{CE}$ runs a very real risk of exacerbating, not alleviating, impending climate change impacts because of its failure to displace primary production (see Zink and Geyer 2017). On similar lines, this paper argues that keeping the CE within the norms, spaces, and mechanisms of consumerism (e.g. SPSSs) will prove problematic and potentially make a dubious contribution to transformation agendas, given research findings to date.

The intention here is to acknowledge the 'dark side' of talk of transformation (Blythe et al. 2018) and then to look for hopeful solutions. Thus, this paper will first explore in greater depth 
the conceptual foundations of the $\mathrm{CE}$, specifically in relation to the 'consumer' and the transformation of quotidian practices. It will then draw on empirical examples from a multidisciplinary project that examined the CE through the creation of new SPSSs for hand-held electronic devices (see Bridgens et al. 2019). Drawing on qualitative data collected as part of this research with members of the UK public, as well as UK and Dutch CE governance and practitioner actors, the paper will underscore the problems of ushering in transformation via SPSSs. It then highlights how spatially local and overtly circular interventions - and the 'small stories' of positive change that emerge from them - can create potentially productive pathways for transforming everyday spaces and practices: ones that challenge some of the norms and practices that many SPSSs currently do not.

\section{Greening 'thinking and lifestyles': the rational consumer of the CE}

\subsection{On the limits of campaigns and green nudging}

There are many schools of thought about how to shift our collective practices to more sustainable options, which arguably hinge upon differing ontological and ethical commitments. For example, eco-philosophers argue that — of all the things that need transforming, as in the EEA quote above - 'thinking' comes first. Here, they are 'seeking a new metaphysics, epistemology, cosmology, and environmental ethics of a person/planet' (Devall 1980, p. 299). While this is laudable, others argue that alterations to worldviews need to come with actionable and directed changes to practices, i.e. 'thinking and lifestyles' (ibid.). For example, 'degrowth' advocates critique the role that economic transactions play in modern human relations (Sekulova et al. 2013) while advocating particular forms of socio-environmental practices, e.g. slow food (e.g. Hall 2012).

Less radical approaches have gained more mainstream acceptance to date, undoubtedly because they sit comfortably within the socio-economic norms of economic growth. Here, the so called weak sustainable consumption focuses on improving the efficiency of goods and services (Lorek and Fuchs 2013) and promoting the 'greening' of the economy, jobs, and consumption: moves that have been roundly critiqued as failing to deliver meaningful transformation and noticeable socio-environmental impact (e.g. Fletcher and Rammelt 2017; Wanner 2015).

A key part of such 'weak' approaches is a focus on the individual and household scale of change. Here, alterations to shopping and home-based practices are advocated on the assumption that lots of small actions add up to significant changes. Here, for example, we are all called upon to heed eco-labels when shopping, power down idle electrics, and/or recycle household waste. Such approaches are exemplified by behaviour change campaigns such as the UK Government's 'Act on $\mathrm{CO}_{2}$ ' campaign, which — along with carbon calculators and manifold lists of how to 'go green' (e.g. see Worldwatch Institute 2006) - are tools that are aimed at making us auditors of our environmental impacts, internalising a specific form of selfmanagement (Soneryd and Uggla 2015).

More recently, green 'nudging' has been trailed, based on the premise of 'policies that maintain or increase freedom of choice' (Thaler and Sunstein 2008, p. 5). Here, interventions are aimed at tapping into apparent human cognitive biases (Schubert 2017), to create small changes to practices that are neither mandatory nor framed in overtly green ways, e.g. reducing plate sizes to cut down on food waste (see Kallbekken 2014; Sachdeva et al. 2015). However, 
to date, these interventions have returned modest positive impacts, raising questions about whether the sometimes less than transparent agendas behind some nudges are ethically acceptable ways of altering public life (see Evans et al. 2017).

Researchers have detailed the measurable outcomes of such interventions. While they can return positive results (e.g. see Gustavsson and Elander 2017; Hausknost et al. 2018), their ability to meaningfully reduce individual and household environmental impacts across services (water, energy, food) is patchy and often make very small — and indeed sometimes partially counter-productive - differences to collective resource uses and disposal (e.g. Changing Markets Foundation 2018; Lawrence and McManus 2008). Indeed, despites decades of these interventions in different forms around the world (but mostly the Global North), consumption of goods and services (e.g. household expenditures, number of consumers, and extraction of raw materials) continues to rise. They show next-to-no sign of abatement in the near future (Worldwatch Institute 2011), with rises in sectors such as global tourism 'effectively outstripping the decarbonisation of tourism-related technology' (Lenzen et al. 2018, no page).

How then are we to foster the transformations of the UN and EEA at the citizen consumer level, if persuading or nudging us all to change does not work? Greening infrastructure, housing retrofits, and more efficient goods and services are part of an at-times effective suite of extant approaches (e.g. Gabriel and Watson 2013). Indeed, these can be viewed as part of arguments for building sustainability into goods and services rather than relying on a voluntary, internalised consumer ethic. Within CE debates, this often takes the form of research into SPSS: a field which will be explored further in the following section.

\subsection{SPSS and designing circularity into CE goods and services}

The CE proposes nothing less than the large-scale transformation of socio-industrial processes (Ellen Macarthur Foundation 2012): an idea that has gained considerable political saliency of late. Influential institutions have taken up CE debates, e.g. World Economic Forum (2019), while China has framed their twenty-first century development plans as being essentially circular (see Yuan et al. 2006). In 2015, the European Commission launched the 'EU Action Plan for the Circular Economy', which states that:

The transition to a more circular economy, where the value of products, materials and resources is maintained in the economy for as long as possible, and the generation of waste minimised, is an essential contribution to the EU's efforts to develop a sustainable, low carbon, resource efficient and competitive economy (European Commission 2015, p. 2)

More recently, the European Commission adopted a Circular Economy Package that includes strategies for reducing plastic use and disposal and new waste reduction and recycling targets (see European Commission 2019). On launching the CE Package, the Italian MEP Simona Bonafè - the EU Parliament's lead on the CE — stated that it 'aims to change the behaviour of businesses and consumers' (see Holder 2018, no page). This is to be done through providing information (e.g. product labelling), price signals, product redesign (re-usability and repairability), and 'innovative forms of consumption' including the SE and consuming services rather than products (European Commission 2015, p. 7).

Some of these suggested mechanisms are nothing new. Product eco-labelling has been around for decades, with mixed results (see Horne 2009; Sammer and Wüstenhagen 2006). 
Sharing and renting goods have an even longer history, replete with cultural legacies and associations, e.g. renting goods as a marker of socio-economic status (Scott 2008). Andalthough there is no space here to explore this in any depth - analyses of the SE paint a less than flattering picture of its social and environmental impacts. There now exists clear data to back up claims that popular forms of the SE, e.g. Airbnb or TaskRabbit, constitute free market encroachment into one's private realms (e.g. our homes or spare time). They also contribute to increasing income inequality, as well as, in some cases, greenhouse gas emissions through 'rebound effects'; e.g., the availability of cheaper (Airbnb) accommodation in European cities means more people are taking short-haul mini-breaks, increasing aviation emissions (e.g. see Hobson and Lynch 2016; Martin 2016; Schor 2017; Slee 2017).

The SE aside, the European Commission's plans to 'servitise' consumption is worthy of further exploration. Although several terms are used, these ideas are aimed at creating services that reduce the material inputs over a product life cycle (Hojnik 2018) or offer 'tangible products and intangible services designed and combined so that they jointly are capable of fulfilling specific customer needs' (Tukker 2004, 246) with less environmental impacts.

Although sometimes coming across as involving nothing more than a dematerialising sleight of hand, such moves arguably require confronting and rethinking the fundamental aims and logics of practices. For example, car sharing schemes are aimed at delivering on-time urban mobility rather than household car ownership, making greater use of existing goods and encouraging users to not make frivolous journeys just because they can. Yet, car ownership is often about a lot more than getting from A to B (e.g. status and freedom), raising questions about whether new business models can recalibrate the deep-seated norms of our material cultures.

In fairness, real-world car sharing schemes have been shown to bring down users' average car-based greenhouse gas emissions (Baptista et al. 2014; Firnkorn and Müller 2011). Other forms of SPSSs have likewise been empirically tested, with less clearly positive outcomes (see Beuren et al. 2013). On the one hand, research has outlined some of the appeals of SPSSs, such as users' ability to upgrade goods regularly (e.g. swapping soiled, rented carpet tiles for new ones), as well as no longer being responsible for their maintenance and upkeep. On the other hand, substantial issues also exist. While they inevitably differ from product to product - as well as being dependent upon the size and site of empirical data collection - findings show similar issues. For example, participants of SPSSs at times struggle to trust the provider and service on offer, as well as having concerns about ease of use, price, and convenience. This is arguably because:

Consumers are accustomed to acquiring products; they are unaccustomed to paying only for their function. Such a cultural change may make many people hesitant about embracing the PSS (Beuren et al. 2013, p. 226).

Overall, this has led to the conclusion that this approach is 'not a panacea for reaching radical factor 4 or 10 environmental improvements' (Tukker 2004, p. 258). As such, rather than being an act of rolling out of a 'new business model' (ibid.) or finessing 'the service encounter' (Rexfelt and Hiort af Ornäs 2009, p. 692), dematerialising goods and services is argued to present deeper challenges to both the practice and theory of transforming our contemporary socio-material relations. As the Beuren et al. quote above suggests (e.g. see also Hobson et al. 2018), moves to create SPSS are endeavouring to go against the norms of consumer practices while remaining within consumerism framing. This is all taking place in a context where everyday talk of the CE is all-but-absent from the public sphere, making the appeal of SPSSs 
reliant upon either the environmental ethics of the user or the ability of a SPSSs to compete in price, convenience, etc. with conventional business models. Can such a project work? The following sections of this paper will explore these issues in greater detail, drawing on empirical material gathered as part of a multi-disciplinary project called 'Closed Loop Emotionally Valuable E-waste Recovery' (CLEVER).

\section{Researching forms of circularity: from mobile phones to Bitterballen}

CLEVER's overall remit was to research pathways for the greater resource efficiency of handheld mobile devices, particularly mobile phones. These were chosen as the focus of CLEVER because consumer electronics is one of the fastest growing sectors in global markets, with smartphones and tablets being the largest growth markets (Euromonitor International 2014). However, much of this technology has very short life spans; e.g., over $60 \%$ of mobile phones are still functional at the time of disposal (Cooper 2004). In addition, it is estimated that only $16 \%$ of electronic waste is recycled or re-used, globally (Baldé et al. 2015): with regulationse.g. EU Directive 2012/19/EU (European Union 2012) which set out Europe's collective electronic waste reduction and recycling targets - failing to resolve this state of affairs. In short, mobile phones can be considered emblematic of the forms of hyper-consumerism that the CE seeks to address.

A key part of CLEVER was investigating how bio-polymer-based materials can be produced and used inside mobile phones, so component parts can be quickly and efficiently accessed for recycling and metal recovery. A later part—based on the possibilities opened up by the bio-polymer work - was to create a hypothetical SPSS (discussed in more detail below) and test potential users' reactions to this SPSS. To that end, 35 semi-structured interviews were conducted during 2016: 20 in London, UK (at the Loughborough University campus in Stratford) and 15 at Loughborough University's main campus. The aim here was to sample a wide range of mobile phone users, not create a representative sample per se. Thus, interviewees ranged between 20 and 70 years old and had a reasonable gender balance, e.g. 12 females and 8 males in the London interviews. All interviews lasted between 20 and 45 min and explored interviewees' understanding of the life cycle of their mobile phone and their reaction to the CLEVER SPSS, when presented by the researchers.

Later in CLEVER, research focus shifted from circular products to the potential of circular spaces/neighbourhoods, and initial work began exploring how institutions overtly labelling themselves as $\mathrm{CE}$ proponents defined and undertook $\mathrm{CE}$ interventions. To that end, 10 interviews were carried out with activists and practitioners in the UK and the Netherlands. A particular focus was placed on Amsterdam due to its political uptake of the CE agenda, including creating a 'roadmap' for the city called Circular Amsterdam (Circle Economy et al. no date). Interviews were conducted over Skype or in person and lasted between 20 minutes and 1 hour, exploring these individuals' experiences of putting the $\mathrm{CE}$ into practice.

\section{From the consumer to the circular citizen? SPSSs and local spaces of circularity}

What, then, were the initial reactions to questions asked of activists and practitioners about their reasons for wanting to forward ideas of the CE? In line with calls for widespread 
transformations, interviewees expressed opinions that the CE was no longer an optional extra or add-on to prevailing systems. Whereas previous discourses and frameworks (e.g. 'sustainable development' and 'green economy') had failed to bring out notable systemic changes, for these interviewees, moves towards the $\mathrm{CE}$ were inevitable and unavoidable. As one interviewee stated:

'The world works circularly, we just think our economy doesn't have to. That's the only stupid assumption we're making, so once we come to our senses and also make the circular economy less of a buzzword and just understand that that is really the only type of economy that will work in the long run, then there is little issue.' (CE Interview 3)

In this context, coming to ones' senses refers to collectively comprehending and acting upon the limits of our finite resources and the impacts of current production-consumption-disposal patterns.

However, some interviewees expressed concern about the CE remaining a 'buzzword' and becoming co-opted as yet another 'greenwashing' PR front for private enterprises. As one interviewee noted: 'There are some key global corporations that are using this term more aggressively now' (CE Interview 8). Here, for profit, institutions are staking out new market territory, eager to be seen as part of apparent progressive changes within capitalism's DNA while doing little to actually reduce the environmental impacts of their goods and services (e.g. see Zink and Geyer 2017). There was some evidence of this from one interviewee who argued that, from the perspective of a business owner:

The circular economy is not about ideology, it is about business, and we like to make business, and when the results are good, we like it even more (CE Interview 10).

On the one hand, the CE certainly is about business. A great deal of the changes needed will have to come from significant alterations to in-house and business-to-business systems, backed up by new technologies, altered standards, and regulatory frameworks (Aldersgate Group 2012). But arguably the CE is inescapably, first and foremost, an ideology: if one takes the definition of this word to be 'a system of ideas and ideals, especially one which forms the basis of economic or political theory and policy' (Oxford University Press 2019, no page). That is, the $\mathrm{CE}$ is formed by a suite of ideas about how to transform current systems. It makes use of particular concepts and vocabularies, e.g. 'disruption' and 'innovation', realised through specific ways of working, e.g. business-to-business and collaborative, enacted via key mechanisms, e.g. price and policy incentives (see Ellen Macarthur Foundation 2012, 2015). These are in turn founded upon ideals of what the future should look like, i.e. prosperous, connected, unwasteful, and sustained (e.g. see European Commission 2015), and assumptions about the human subject and how to change our behaviours. The next sub-section explores this latter point further, arguing that the CE presents the consumer/user as an overly rational and dematerialised subject, rather than one deeply embedded in the 'longue durée' of complex socio-material relations.

\subsection{Consuming the CE: designing sustainability into systems}

The role of individuals as consumers/users has received less attention than other aspects of the $\mathrm{CE}$ (e.g. technological interventions) within mainstream debates to date. This may be in part 
because the $\mathrm{CE}$ has roots in decade-old work that has historically had little focus on the end user (e.g. industrial ecology). When the consumer is included in the CE, 'we' are, for the most part, discussed as social entities that now must form new relations with businesses to meet our unchallenged material needs and consumerist urges. That is, as 'the circular economy largely replaces the concept of a consumer with that of a user' (Ellen Macarthur Foundation 2012, p. 7), who must either accept or reject new business models, stimulated by the pushes and pulls of prices and 'product performance' (Ellen Macarthur Foundation 2012, p. 7).

And this is where the CE has to date run into challenges (see also Tukker 2004). For example, CLEVER research interviewees outlined how mainstreaming forms of circularity that require voluntary consumer uptake has proven problematic. As one interviewee noted, when talking about the UK high street retailer Argos' introduction of an electronics 'take back' scheme:

The biggest challenge they had was trying to figure out how can they market this in a way to bring the consumer on board. And also just so that consumers even knows that the service...But a lot of it has been how do you frame this to a consumer in a way that's interesting to them. Because obviously being resource efficient isn't necessarily a parameter that you have when you're buying things. (CE Interview 2)

This quote echoes broader research into the challenges of altering high street purchasing practices, which has shown that environmental issues need to be salient and of overt concern to the individual when making purchases (Sachdeva et al. 2015). Although the obvious solution here would be to provide prompting information at the point of retail (e.g. labelling, in-store advertising), this necessitates that individuals are able and willing to make connections between their own practices (e.g. buying a new toaster) and appeals for them to participate in 'add on' schemes (e.g. store take backs), which may not be immediately obvious and appealing. Even for those who have salient environmental concerns, there is a persistent finding of a value-action gap (Moser 2015), fuelled by the complexities of evaluating the best course of action amidst all the other pressures and entanglements of daily life (Hobson et al. 2018).

For some proponents of the $\mathrm{CE}$, one way to partially circumvent this complex terrain of contexts, personal choices, and social norms is to embed system transformations into new SPSSs via robust design. The logic at work here is often backed up by the much quoted, but hard to substantiate, assertion 'that over $80 \%$ of all product-related environmental impacts are determined during the design phase of a product' (EU Science Hub 2016, no page; see also Aldersgate Group 2012). Thus, building transformations into SPSSs has support: such as from one CLEVER interviewee who talked about a short-distance electric car club in the Netherlands. This club has been marketed without overt environmental framings, attempting instead to normalise CE practices by producing a well-designed, good-quality, sharing scheme. As this interviewee says about Dutch consumers and their willingness and ability to partake in such schemes:

They learn it now because of all these sharing initiatives all over the country and that is a strong development. But we don't tell them too often that it is about circular economy or whatever...It is a way that they can use good products. (CE Interview 10)

Although the above example is one apparent success story, for the most part, the SPSS literature has underscored how creating new business models that deliver a 'good product' 
with lower environmental impacts has proven challenging across sectors (see Tukker 2004). One reason for this may lie in how consuming - and its relation to the $\mathrm{CE}$ - is being understood and conceptualised by advocates of the CE. For example, one interviewee made the observation that:

It's good to distinguish circularity situations which are exclusively technical and ones in which technology and kinds of social circularity are combined (CE Interview 11)

An 'exclusively technical' situation could pertain, at first glance, to making appliances more energy efficient, requiring little or no changes to practices. However, social theorists who examine contemporary human-material relations may question if there is ever an exclusively technical solution (e.g. see Shove 2003). Even if one purchases an energy-efficient washing machine, its use is still informed by-and over time informssocial expectations and norms about cleanliness, etc. As such, new forms of SPSS that involve a 'user' also involve some element of 'social circularity', which brings into question any distinction between the social and technical in relation to the consumer and the CE.

\subsection{Society and technology in the CE}

To explain further, arguably there is an under-theorisation of socio-technical relations at the heart of the $\mathrm{CE}$, which gives rise to some of the challenges in making it a reality. For one, debates about SPSS and 'servitisation' appear to assume that current material-based practices are interchangeable with services, which are able to be made (nearly) equivalent in terms of experience and outcomes. By this logic, our contemporary material cultures are fundamentally real-world manifestations of, and the means by which we meet, pre-determined needs (e.g. connectivity and warmth): needs that can be met by other means (i.e. non-good-based services). While no doubt there is some truth in that argument, it underestimates the extent to which-as archaeologists studying material culture have put it—'things make people' (González-Ruibal 2012, no page). That is, we both make and are made (as social entities) by our material worlds across our own lifetimes but also through the longer course of history. Here, the technology and materials around us all are argued as the key to shaping our cognitive processes and social relations. In short, we think through and with the 'stuff' of the everyday, and thus, replacing them with dematerialised services may neither appeal nor always be feasible.

Beyond archaeologists dealing with the longue durée of human evolution, sociological research supports this point, particularly work utilising social practice theories to examine everyday relations with contemporary material cultures (e.g. Shove 2003; Mylan 2015). This (often) ethnographically focussed research shows how, rather than just meeting basic needs, our modern technological contexts - some of which we may barely notice, e.g. heating and cooling homes - have shaped our expectations and social norms of the everyday, e.g. a home with thermal comfort.

In this context, altering individual behaviour and consumption practices - as framed by CE proponents - assumes that all of our actions are open to conscious choices, and our personal agency is paramount in the face of quotidian decisions (Butler et al. 2016). However, research argues that practices are: 
intertwined configurations of material, competency, social relations and cultural meaning, and thus individuals... are conceptualized as the carriers of social practices... and can hardly to be expected to lead and cause social change (Jalas et al. 2017, p. 78).

In short, for the $\mathrm{CE}$ consumer-user, we need to consider how the ability to adopt new practices is highly circumscribed by social, material, and cultural configurations.

This point is evidenced by findings from CLEVER research, particularly the interviews with members of the UK public that focussed on a proposed mobile phone SPSS. The interviews highlighted how the participants - while broadly supportive of altering consumption practices to limit human rights violations and environmental damage — had many issues with potentially enacting the proposed SPSS (see Hobson et al. 2018 for further information). In brief, the proposed SPSS was designed so the participant owned only the phone's outer layer or 'skin' as the CLEVER project called it, which could be customised as the owner saw fit. The internal components ('skeleton' and 'guts') are, by contrast, leased and need to be returned regularly by the participant to a convenient high street drop-off point for rapid recycling and upgrading. The rationale here is that - given the rapid growth in the purchase and disposal of consumer electronics (see Lane et al. 2018) - this SPSS captures some of the precious resources inside mobile phones, often lost from value chains due to inadequate postuse disposal or long-term 'hibernation' (see Wilson et al. 2017).

On the surface, the required changes to individual practices seem minor. The new SPSS requires only that participants part with their phone for an estimated 1-2 $\mathrm{h}$ every year or so. And yet issues of trust, convenience, and pricing presented substantial barriers to its reported potential uptake. Participants - while acknowledging the negative environmental and human rights issues linked to the production of electrical goods - struggled to make connections between these geographically distant concerns and their own immediate needs, particularly given broader social expectations of constant connectivity. In addition, the idea of being a 'user' or a renter of part of a phone did not appeal to many, as the rationale did not resonate in the absence of broader, supporting discourses, e.g. the $\mathrm{CE}$ and/or resource scarcity. In short, as the ubiquitous smartphone has been the key to creating heightened expectations of convenience via connectivity (finding information, connecting with others via talk or text), any SPSS that pushes back at this, perceived as causing even very minor inconveniences, is not met with great enthusiasm.

This may just be down to the particular challenge of altering the mobile phone life cycle. But returning to archaeology, the assertion that 'cognitive processes are distributed among people and things' (González-Ruibal 2012, no page) resonates here. For example, recent research suggests that humans increasingly 'offload thinking to technology'; e.g., those relying on smartphones for information appear to think less analytically than those who do not (Barr et al. 2015). This leads some to the profound but understated conclusion that there is thus a need to rethink how to 'adequately characterize human experience and cognition in the modern era' (Barr et al. 2015, p. 473).

Does such a statement lead inevitably towards going with the grain of this 'modern era', embracing hyper-technological solutions to issues like climate change, which are often prefixed with the word 'smart' (e.g. city, home, and meter)? While there are already numerous critiques of, and evidence against, this further reliance upon outsourcing our practices (e.g. Hargreaves et al. 2010; Goulden et al. 2018), it is still evident that if one thinks about the various practices written through the $\mathrm{CE}$ (i.e. repair, sharing, and refurbishing), these cannot be achieved by 'smart technology' alone. 
When talking about the essence of the CE, one interviewee noted that:

There is the tendency to just look at the hardware. They have a smart new sewage system "Let's try that elsewhere". It's just the hardware. But when it comes to circular economy and how people have different roles...you really need to look very carefully at what's already there and... what values they are creating. (CE Interview 1)

And this is where insight into such values - and the forms of 'social circularity' they engender — can be illuminating, when thinking about how 'fundamental transitions...in core systems' (ibid.) can be realised in everyday practices and spaces. For example, among the CLEVER research interviewees was a social enterprise employee whose organisation shares and repairs everyday and specialised goods. Talking about their organisation's goals, this person noted that:

We decided very early on to concentrate on what we call the inner circle of the circular economy which is not so much about design or disassembly but it's about the services or skills that are needed to make the most of a product during its current cycle life, and the desire to see the re-emergence of repair not just as a hobby, but as a viable activity. (CE Interview 8)

Such viability — of an active involvement of individuals in the upkeep and repair of their goods - is no doubt contingent upon many things. This includes space, time, capabilities and skill sets, and a desire to actively participate in repair practices (see Dewberry et al. 2016): not something that appeals to everyone (Smith and Light 2017). However, with the rise of organisations such as voluntary repair cafes (now numbered at 1896 around the world; see Repair Cafe 2019) - and growing attention to the repairability of electronic goods such as in the free IFixit website, which contains over 51,715 repair manuals - there are potentially significant shifts already taking place. Are individuals doing more than just repairing toasters and clothes, one piece at a time? Potentially, they are reconfiguring everyday material relations from one of use and disposal to one of care and stewardship. This latter concept can be argued as part of our current 'sense of responsibility to materials and care for things' (Lane and Watson 2012, p. 1261) - e.g. family heirlooms and hobby materials. A key question is whether this perspective can be broadened to include more mundane objects that can in turn become part of one's long-term material landscape, undergirded by, for example, emotional attachment (see Chapman 2009).

Admittedly these arguments are nascent and require further exploration, but it is clear that such shifts are hard to achieve by designing/making tacitly goods and services the rationales and goals of the CE. Rather, overt and meaningful strategies, embedded in the everyday, need to be deployed as well. To underscore this point, the final section of this paper draws on interviews with key actors in the creation of the Amsterdam neighbourhood of Buiksloterham, to explore other pathways to achieving everyday social circularity.

\subsection{Small stories of everyday circularity}

Buiksloterham is a post-industrial area of Amsterdam, on the northern banks of the River IJ, just across the water from Amsterdam Central Station. While there is unfortunately no space in this paper to discuss the history of Buiksloterham, its inclusion here is due to 
ongoing collaboration between the City of Amsterdam and 20 organisations, with the aim that:

Over the next 10 years, Buiksloterham will be transformed into a circular neighbourhood where products and raw materials are reused as much as possible (https://amsterdamsmartcity.com/projects/circulair-buiksloterham; see also Metabolic et al. 2014).

A lot could be said about the process and challenges of such an undertaking, from a governance and technical perspective (see Dembski 2013). However, here the key insight, most relevant to this paper, comes from one of the spaces in this neighbourhood called De Ceuvel. This site was established as a 'workplace for creative and social enterprises' in the former shipyard area, now comprising work spaces and a cafe (De Ceuval no date). The site runs on closed-loop principles, in terms of its energy and nutrient flows, with production and waste systems interlinked. As one interviewee outlined, explaining the site:

You have people eating, people shitting, and plants growing, and trying to capture that all on one site. It's a beautiful idea and I don't think it happens in a lot of places. So now we have the biogas boat. We have our own greenhouse and we have a composting facility for our bio-waste, and we have the café and the kitchen which cook on the produce from our greenhouse which is grown from the compost that we produce ourselves and all the rest of the compost is used to generate biogas in which we cook again. So that's a lot of small loops and together, they close a big loop. (Interview 7)

And these small loops are not just about the ecosystems of the site. De Ceuvel aims are overt, to 'make sustainability creative, accessible and fun for everyone' (ibid.). Rather than doing this through abstract information or favourable pricing structures in the work spaces or cafe, overt links are made between seemingly small and mundane facets of consumption and the principles of the CE. As this interviewee went on to explain:

We have this traditional snack called Bitterballen...normally it's kind of a crispy ball filled with Ragu and traditionally the Ragu is made from veal. Well veal is not really sustainable product, so there's this company, GRO, that makes these mushroom, that makes Bitterballen from mushrooms. I tell this to people that are coming here to eat about all these small stories, about how we're closing loops. Then it gets really more visual for people and they can also taste it, so that a circular economy and sustainability isn't something from the elite or a higher class of people...it's really actually there and that there's people working on it and if you just make an effort to do something about it then there's so many possibilities. (CE Interview 6)

While arguably the above entails no great effort on the part of the consumer (i.e. buying the Bitterballen or not), this example illustrates the way that such 'small stories' can play a particular role. However, this story would arguably be less potent if told and heard in isolation from the context of De Ceuvel and Buiksloterham and quite possibly larger discourses and outcomes about development in twenty-first century Amsterdam and the Netherlands (e.g. see Savini et al. 2016). That is, while exhortations to participate in in-store take back schemes take place in a context of prevailing hyper-consumerism, the Bitterballen story is part of a larger 
narrative - and physical space - that speaks to the CE as a lived and seen experience in the everyday. Of course, not everywhere can become De Ceuvel overnight, if at all: that is not the point of this example. Rather, it gives some (tentative and to be expanded upon) insight into an argument that a CE that is aimed at making goods and services more sustainable, one SPSS at a time, fails to understand the importance of context, complex socio-technical relations, and broader social currents, in getting us all on board, as part of a CE transformative agenda that lands with some impact in our everyday lives.

\section{Concluding comments}

Research has shown repeatedly how difficult it is to make global issues like climate change meaningful in our everyday lives and thus instrumental in changing practices (e.g. see Norgaard 2011). While climate change-along with resource scarcity and security issues - underpins transformative projects like the $\mathrm{CE}$, current approaches tend to favour hiding the principles of the $\mathrm{CE}$ behind the normalised mechanisms used to affect consumption and use practices, e.g. price structure and service delivery. As creating sellable and low-environmental impact SPSS has proven challenging to date (Tukker 2004; Hobson et al. 2018), it appears that the way forward currently contains a few options. One is to focus on driving material efficiencies and service mechanisms further, in the hope of achieving a truly sustainable SPSS - a trajectory certainly supported under the current mainstream iteration of the CE. But, as illustrated with the mobile phone example above, this does not mean consumers are willing to participate in the new SPSSs that ensue. The other option is where overt 'circular stories' like the Bitterballen example come in, as small but comprehensible steps in making 'an effort to do something' as one interviewee put it. Indeed, Sachdeva et al. (2015) have argued that - in terms of the psychology of 'green consumerism' - a sense of 'constructive optimism' is pivotal to making positive practice changes.

The question then becomes one of how to implement interventions that foster such optimism and lessen negative environmental impacts, in the face of talk of pending climate crises. For one, such considered and interlinked examples like De Ceuvel cannot be undertaken by voluntary labour and goodwill alone, as many local sustainability interventions are. Given the considerable political attention, along with financial input, the $\mathrm{CE}$ has been garnering of late; there is arguably thus a need to reclaim it as not just a business and policy endeavour but a thoroughly civic one too and one that is firmly undergirded by public funding. While public spending agendas like the New Green Deal focus primarily on energy systems, funding for spaces like, for example, repair cafes or 'circular spaces' like De Ceuvel can arguably be fruitful experiences of forms of first-hand social circularity, which potentially create an openness to other forms of practice change (e.g. domestic purchasing and disposal) in our everyday lives. Our jobs - as researchers, practitioners, and consumer citizens - are to illuminate the potency of broadening out the CE framework, so that our collective ability to participate in called-for transformations is not limited to just the shopping mall or the recycling bin.

Funding information This research was supported by the Engineering and Physical Sciences Research Council (EPSRC) as part of the Closed Loop Emotionally Valuable E-waste Recovery (CLEVER) project, funded under grant number $\mathrm{EP} / \mathrm{K} 026380 /$. 
Open Access This article is distributed under the terms of the Creative Commons Attribution 4.0 International License (http://creativecommons.org/licenses/by/4.0/), which permits unrestricted use, distribution, and reproduction in any medium, provided you give appropriate credit to the original author(s) and the source, provide a link to the Creative Commons license, and indicate if changes were made.

\section{References}

Aldersgate Group (2012) Resilience in the round: seizing the growth opportunities of a circular economy. http://www.aldersgategroup.org.uk/asset/458. Accessed 1 August 2018

Baldé CP, Wang F, Kuehr R, Huisman J (2015) The global e-waste monitor - 2014. United Nations University, IAS - SCYCLE, Bonn, Germany

Baptista P, Melo S, Rolim C (2014) Energy, environmental and mobility impacts of car-sharing systems. Empirical results from Lisbon, Portugal. Procedia Soc Behav Sci 111:28-37. https://doi.org/10.1016/j. sbspro.2014.01.035

Barr N, Pennycook G, Stolz JA, Fugelsang JA (2015) The brain in your pocket: evidence that smartphones are used to supplant thinking. Comput Hum Behav 48:473-480. https://doi.org/10.1016/j.chb.2015.02.029

Beck S, Mahony M (2018) The IPCC and the new map of science and politics. Wiley Interdiscip Rev Clim Chang 9(6):e547. https://doi.org/10.1002/wcc.547

Beuren FH, Ferreira MGG, Miguel PAC (2013) Product-service systems: a literature review on integrated products and services. J Clean Prod 47:222-231

Blythe J, Silver J, Evans L, Armitage D, Bennett NJ, Moore ML, Brown K (2018) The dark side of transformation: latent risks in contemporary sustainability discourse. Antipode 50(5):1206-1223. https://doi.org/10.1111/anti.12405

Bridgens B, Hobson K, Lilley D, Lee J, Scott J, Wilson G (2019) Closing the loop on e-waste: a multidisciplinary perspective. J Ind Ecol 23(1):169-181. https://doi.org/10.1111/jiec.12645

Butler C, Parkhill KA, Pidgeon NF (2016) Energy consumption and everyday life: choice, values and agency through a practice theoretical lens. J Consum Cult 16:887-907. https://doi.org/10.1177/1469540514553691

Changing Markets Foundation (2018) The false promise of certification. https://changingmarkets.org/wpcontent/uploads/2018/05/False-promise_full-report-ENG.pdf. Accessed 3 August 2018

Chapman J (2009) Design for (emotional) durability. Des Issues 25:29-35. https://doi.org/10.1162 /desi.2009.25.4.29

Circle Economy, Fabric TNO, Amsterdam G (no date) Circular Amsterdam: a vision and action agenda for the city and metropolitan region. https://www.circle-economy.com/wp-content/uploads/2016/04/CircularAmsterdam-EN-small-210316.pdf. Accessed 2 August 2018

Cooper T (2004) Inadequate life? Evidence of consumer attitudes to product obsolescence. J Consum Policy 27(4):421-449. https://doi.org/10.1007/s10603-004-2284-6

De Ceuval (no date) What is De Ceuval? http://deceuvel.nl/en/about/general-information. Accessed on 29 May 2019

Dembski S (2013) Case study Amsterdam Buiksloterham, the Netherlands: the challenge of planning organic transformation. Context Report 2. AISSR programme group Urban Planning, Amsterdam. https://pure.uva. nl/ws/files/1523659/124693_CONTEXT_Report_2.pdf. Accessed 3 August 2018

Devall B (1980) The deep ecology movement. Nat Resour J 20:299-322

Dewberry EL, Saca L, Moreno M, Sheldrick L, Sinclair M, Makatsoris C, Charter M A (2016) Landscape of repair. In proceedings of the sustainable innovation. Circular economy innovation and design. Towards sustainable product design, The Centre for Sustainable Design, University of the Creative Arts, Epsom, Surrey, UK:76-85

Ellen MacArthur Foundation (2012) Towards the circular economy vol. 1: an economic and business rationale for an accelerated transition. https://www. ellenmacarthurfoundation. org/assets/downloads/publications/Ellen-MacArthur-Foundation-Towards-the-Circular-Economy-vol.1.pdf. Accessed 3 August 2018

Ellen Macarthur Foundation (2015) Growth within: a circular economy vision for a competitive Europe. https://www.ellenmacarthurfoundation.org/assets/downloads/publications/EllenMacArthurFoundation Growth-Within_July15.pdf. Accessed 3 August 2018

Ellen MacArthur Foundation (2017) Borrow stuff you need. Lend stuff you don't. https://www. ellenmacarthurfoundation.org/case-studies/borrow-stuff-you-need-lend-stuff-you-dont. Accessed 27th May 2019

Euromonitor International (2014) Euromonitor International, 2014. Consumer electronics: outlook, trans and analysis. Global Briefing Sept. http://www.euromonitor.com/consumerelectronics-outlook-trends-andanalysis/report. Accessed 27 May 2019 
EU Science Hub (2016) Sustainable product policy. https://ec.europa.eu/jrc/en/research-topic/sustainableproduct-policy. Accessed 3 August 2018

European Commission (2015) Closing the loop - an EU action plan for the circular economy. Communication from the Commission to the European Parliament, the Council, the European Economic and Social Committee and the Committee of the Regions. https:/eur-lex.europa.eu/resource.html?uri=cellar:8a8ef5e899a0-11e5-b3b7 01aa75ed71a1.0012.02/DOC 1\&format=PDF. Accessed 1 August 2018

European Commission (2019) Circular economy: implementation of the circular economy action plan. http://ec. europa.eu/environment/circular-economy/index_en.htm. Accessed 28 May 2019

European Union (2012) Directive 2012/19/EU of the European Parliament and of the Council of 4 July 2012 on waste electrical and electronic equipment (WEEE). http://eur-lex.europa.eu/legal-content/EN/TXT/?uri= celex\%3A32012L0019. Accessed 27 May 2019

European Environment Agency (2018) Perspectives on transitions to sustainability. EEA Report No 25/2017, Copenhagen. https://www.eea.europa.eu/publications/perspectives-on-transitions-to-sustainability/file. Accessed 1 August 2018

Evans N, Eickers S, Geene L, Todorovic M, Villmow A (2017) Green nudging: a discussion and preliminary evaluation of nudging as an environmental policy instrument. Environmental Policy Research Centre (FFU) Freie Universität BerlinVersion: FFU-report 01-2017. https://doi.org/10.13140/RG.2.2.35588.63369

Fletcher R, Rammelt C (2017) Decoupling: a key fantasy of the post-2015 sustainable development agenda. Globalizations 14:450-467. https://doi.org/10.1080/14747731.2016.1263077

Firnkorn J, Müller M (2011) What will be the environmental effects of new free-floating car-sharing systems? The case of car2go in Ulm. Ecol Econ 70(8):1519-1528. https://doi.org/10.1016/j.ecolecon.2011.03.014

Fuchs D, Lorek S (2005) Sustainable consumption governance: a history of promises and failures. J Consum Policy 28(3):261-288. https://doi.org/10.1007/s10603-005-8490-z

Gabriel M, Watson P (2013) From modern housing to sustainable suburbia: how occupants and their dwellings are adapting to reduce home energy consumption. Hous Theory Soc 30:219-236. https://doi.org/10.1080 /14036096.2013.775183

González-Ruibal A (2012) Archeology and the study of material culture: synergies with cultural psychology. In Valsiner J (ed.) The Oxford handbook of culture and psychology, http://www.oxfordhandbooks. com/view/10.1093/oxfordhb/9780195396430.001.0001/oxfordhb-9780195396430-e-8. Accessed 25 July 2018

Goulden M, Spence A, Wardman J, Leygue C (2018) Differentiating 'the user' in DSR: developing demand side response in advanced economies. Energy Policy 122:176-185. https://doi.org/10.1016/j.enpol.2018.07.013

Gustavsson E, Elander I (2017) Behaving clean without having to think green? Local eco-technological and dialogue-based, low-carbon projects in Sweden. J Urban Technol 24:93-116. https://oi.org/10.1080 $/ 10630732.2016 .1175806$

Hall CM (2012) The contradictions and paradoxes of slow food: environmental change, sustainability and the conservation of taste. In: Fullagar S, Markwell K, Wilson E (eds) Slow tourism: experiences and mobilities, Channel View Publications, pp 53-68

Hargreaves T, Nye M, Burgess J (2010) Making energy visible: a qualitative field study of how householders interact with feedback from smart energy monitors. Energy Policy 38(10):6111-6119. https://doi. org/10.1016/j.enpol.2010.05.068

Hausknost D, Haas W, Hielscher S, Schäfer M, Leitner M, Kunze I, Mandl S (2018) Investigating patterns of local climate governance: how low-carbon municipalities and intentional communities intervene in social practices. Environ Policy Gov 28:371-382. https://doi.org/10.1002/eet.1804

Hobson K, Lynch N (2016) Diversifying and de-growing the circular economy: radical social transformation in a resource-scarce world. Futures 82:15-25. https://doi.org/10.1016/j.futures.2016.05.012

Hobson K, Lynch N, Lilley D, Smalley G (2018) Systems of practice and the circular economy: transforming mobile phone product service systems. Environ Innov Soc Trans 26:147-157. https://doi.org/10.1016/j. eist.2017.04.002

Hojnik J (2018) Ecological modernization through servitization: EU regulatory support for sustainable productservice systems. Rev Eur Comp Int Environ Law 27:101-204. https://doi.org/10.1111/reel.12228

Holder M (2018) EU circular economy plans clear major hurdle after MEP approval. BusinessGreen. https:/www.businessgreen.com/bg/news-analysis/3030475/eu-circular-economy-plans-clear-major-hurdleafter-mep-approval. Accessed 3 August 2018

Horne RE (2009) Limits to labels: the role of eco-labels in the assessment of product sustainability and routes to sustainable consumption. Int J Consum Stud 33(2):175-182. https://doi.org/10.1111/j.14706431.2009.00752.x

Intergovernmental Panel on Climate Change (2018) Global warming of $1.5^{\circ} \mathrm{C}$ : an IPCC special report on the impacts of global warming of $1.5^{\circ} \mathrm{C}$ above pre-industrial levels and related global greenhouse gas emission 
pathways, in the context of strengthening the global response to the threat of climate change, sustainable development, and efforts to eradicate poverty. Intergovernmental panel on climate change

Interface (2019) Climate take back. https://www.interface.com/EU/en-GB/campaign/climate-take-back/ClimateTake-Back-en_GB. Accessed 27th May 2019

Jackson T (2009). Prosperity without growth: economics for a finite planet. Routledge

Jalas M, Hyysalo S, Heiskanen E, Lovio R, Nissinen A, Mattinen M, Rinkinen J, Juntunen JK, Tainio P, Nissilä H (2017) Everyday experimentation in energy transition: a practice-theoretical view. J Clean Prod 169:7784. https://doi.org/10.1016/j.jclepro.2017.03.034

Kallbekken S (2014) Green nudges: can smileys on your utility bill reduce global emissions? The Guardian, The Guardian Friday 25 April. https:/www.theguardian.com/sustainable-business/behavioural-insights/greennudges-behaviour-change-reduce-emissions. Accessed 10 July 2018

Lane R, Watson M (2012) Stewardship of things: the radical potential of product stewardship for re-framing responsibilities and relationships to products and materials. Geoforum 43:1254-1265. https://doi. org/10.1016/j.geoforum.2012.03.012

Lane R, Follett K, Lindsay J (2018) Unsustainable trajectories of domestic information technology use in Australia: exploring diversity and the life course. Geogr J 184(4):357-368. https://doi.org/10.1111 /geoj.12260

Lawrence K, McManus P (2008) Towards household sustainability in Sydney? Impacts of two sustainable lifestyle workshop programs on water consumption in existing homes. Geogr J 46:314-332. https:/doi. org/10.1111/j.1745-5871.2008.00526.X

Lenzen M, Sun Y, Faturay F, Ting Y, Geschke A, Malik A (2018) The carbon footprint of global tourism. Nat Clim Chang 8:522-528. https://doi.org/10.1038/s41558-018-0141-X

Liedtke C, Baedeker C, Hasselkuß M, Rohn H, Grinewitschus V (2015) User-integrated innovation in sustainable LivingLabs: an experimental infrastructure for researching and developing sustainable product service systems. J Clean Prod 97:106-116. https://doi.org/10.1016/j.jclepro.2014.04.070

Lorek S, Fuchs S (2013) Strong sustainable consumption governance-precondition for a degrowth path? J Clean Prod 38:36-43. https://doi.org/10.1016/j.jclepro.2011.08.008

Martin CJ (2016) The sharing economy: a pathway to sustainability or a nightmarish form of neoliberal capitalism? Ecol Econ 121:149-159. https://doi.org/10.1016/j.ecolecon.2015.11.027

Metabolic, Studioninedots and DELVA Landscape Architects (2014) Circular Buiksloterham: Vision and Ambition. https://buiksloterham.nl/engine/download/blob/gebiedsplatform/69870/2015/28 /CircularBuiksloterham_ENG_FullReport_05_03_2015.pdf?app=gebiedsplatform\&class=9096\&id=63 \&field=69870. Accessed 4 July 2019

McBain B, Lenzen M, Wackernagel M, Albrecht G (2017) How long can global ecological overshoot last? Glob Planet Chang 155:13-19. https://doi.org/10.1016/j.gloplacha.2017.06.002

Moser AK (2015) Thinking green, buying green? Drivers of pro-environmental purchasing behavior. J Consum Mark 32:167-175. https://doi.org/10.1108/JCM-10-2014-1179

Mylan J (2015) Understanding the diffusion of sustainable product-service systems: insights from the sociology of consumption and practice theory. J Clean Prod 97:13-20. https://doi.org/10.1016/j.jclepro.2014.01.065

Norgaard KM (2011) Living in denial: climate change, emotions, and everyday life. MIT Press

Oxford University Press (2019) Ideology. https://en.oxforddictionaries.com/definition/ideology. Accessed 29 May 2019

Pool U (2018) Removing GDP from the equation: integrating health and wellbeing into national development metrics. Br Med J 363:k4371

Raworth K (2018) Doughnut economics: seven ways to think like a 21st-century economist. Random House Business Books, London

Repair cafe (2019) visit a repair cafe. https://repaircafe.org/en/visit. Accessed on 28 May 2019

Rexfelt O, Hiort af Ornäs V (2009) Consumer acceptance of product-service systems: designing for relative advantages and uncertainty reductions. J Manuf Technol Manag 20:674-699. https://doi.org/10.1108 $/ 17410380910961055$

Robin R (2000) Sustainable product-service systems. Futures 32:289-299. https://doi.org/10.1016/S0016-3287 (99)00098-1

Sachdeva S, Jordan J, Mazar N (2015) Green consumerism: moral motivations to a sustainable future. Curr Opin Psychol 6:60-65. https://doi.org/10.1016/j.copsyc.2015.03.029

Sammer K, Wüstenhagen R (2006) The influence of eco-labelling on consumer behaviour-results of a discrete choice analysis for washing machines. Bus Strateg Environ 15:185-199. https://doi.org/10.1002/bse.522

Savini F, Boterman WR, Van Gent WP, Majoor S (2016) Amsterdam in the 21st century: geography, housing, spatial development and politics. Cities 52:103-113. https://doi.org/10.1016/j.cities.2015.11.017

Schubert C (2017) Green nudges: do they work? Are they ethical? Ecol Econ 132:329-342. https://doi. org/10.1016/j.ecolecon.2016.11.009 
Scott P (2008) Marketing mass home ownership and the creation of the modern working-class consumer in interwar Britain. Bus Hist 50(1):4-25. https://doi.org/10.1080/00076790701785581

Schor JB (2017) Does the sharing economy increase inequality within the eighty percent?: findings from a qualitative study of platform providers. Camb J Reg Econ Soc 10(2):263-279. https://doi.org/10.1093 /cjres/rsw047

Sekulova F, Kallis G, Rodríguez-Labajos B, Schneider F (2013) Degrowth: from theory to practice. J Clean Prod 38:1-6. https://doi.org/10.1016/j.jclepro.2012.06.022

Seyfang G, Longhurst N (2016) What influences the diffusion of grassroots innovations for sustainability? Investigating community currency niches. Tech Anal Strat Manag 28(1):1-23. https://doi.org/10.1080 $/ 09537325.2015 .1063603$

Shove E (2003) Converging conventions of comfort, cleanliness and convenience. J Consum Policy 26:395-418. https://doi.org/10.1023/A:1026362829781

Shove E, Walker G (2007) Caution! Transitions ahead: politics, practice, and sustainable transition management. Environ Plan A 39:763-770. https://doi.org/10.1068/a39310

Smith A, Light A (2017) Cultivating sustainable developments with makerspaces. Liinc em revista 13:162-174. https://doi.org/10.18617/liinc.v13i1.3900

Slee T (2017) What's yours is mine: against the sharing economy. Or Books

Smith A, Fressoli M, Thomas H (2014) Grassroots innovation movements: challenges and contributions. J Clean Prod 63:114-124. https://doi.org/10.1016/j.jclepro.2012.12.025

Soneryd L, Uggla Y (2015) Green governmentality and responsibilization: new forms of governance and responses to 'consumer responsibility'. Environ Politics 24(6):913-931. https://doi.org/10.1080 /09644016.2015.1055885

Steffen W, Richardson K, Rockström J, Cornell SE, Fetzer I, Bennett EM, Biggs R, Carpenter SR, de Vries W, de Wit CA, Folke C, Gerten D, Heinke J, Mace GM, Persson LM, Ramanathan V, Reyers B, Sörlin S (2015) Planetary boundaries: guiding human development on a changing planet. Science 347:736. https://oi. org/10.1126/science.1259855

Thaler R, Sunstein C (2008) Nudge. The politics of libertarian paternalism, New Haven

Tukker A (2004) Eight types of product-service system: eight ways to sustainability? Experiences from SusProNet. Bus Strateg Environ 13:246-260. https://doi.org/10.1002/bse.414

United Nations (2015) Transforming our world: the 2030 agenda for sustainable development. United Nations, Rome

Urban Transitions Alliance (2019) Urban transitions. https://urbantransitions.org. Accessed 28 May 2019

Wanner T (2015) The new 'passive revolution' of the green economy and growth discourse: maintaining the 'sustainable development' of neoliberal capitalism. New Political Econ 20:21-41. https://doi.org/10.1080 /13563467.2013.866081

Wilson GT, Smalley G, Suckling JR, Lilley D, Lee J, Mawle R (2017) The hibernating mobile phone: dead storage as a barrier to efficient electronic waste recovery. Waste Manag 60:521-533. https://doi.org/10.1016 /j.wasman.2016.12.023

World Economic Forum (2019) Platform for accelerating the circular economy. https://www.weforum. org/projects/circular-economy. Accessed 28 May 2019

Worldwatch Institute (2006) 10 ways to go green and save green. http://www.worldwatch.org/resources/go_ green save green. Accessed 28 May 2019

Worldwatch Institute (2011) State of the world 2011: innovations that nourish the planet. The Worldwatch Institute, Washington, D.C.

Yuan Z, Bi J, Moriguichi Y (2006) The circular economy: a new development strategy in China. J Ind Ecol 10(12):4-8. https://doi.org/10.1162/108819806775545321

Zink T, Geyer R (2017) Circular economy rebound. J Ind Ecol 21(3):593-602. https://doi.org/10.1111/jiec.12545

Publisher's note Springer Nature remains neutral with regard to jurisdictional claims in published maps and institutional affiliations. 